\title{
Synthesis of PQ with its Redox Properties
}

\author{
Pratima V. Damre', Dr. V. M. Raut ${ }^{2}$ \\ ${ }^{1}$ Government College of Engineering and Research Awsari(khurd) Taluka-Ambegao, Dist-Pune. \\ ${ }^{2}$ Government Vidarbh Institute of Science and Humanities,Amravati
}

\begin{abstract}
The thermal, electrochemical, photophysical, and electroluminescent properties of the new polyquinolines varied with the arylene linkage, including p-phenylene, 4, 4'-biphenylene, stilbene, 5, 5'-bithienylene, bis(thienyl)vinylene, and3, 7-phenothiazinylene. The new conjugated polymers combined high glass transition temperature $\left(110-254{ }^{\circ} \mathrm{C}\right)$ with quasireversible electrochemical reduction from which 2.72-3.00 $\mathrm{eV}$ electron affinities were estimated. The optical band gap varied from 2.19 to $2.86 \mathrm{eV}$ whereas the photoluminescence emission maximum varied from blue-green $(477 \mathrm{~nm})$ to deep red $(646 \mathrm{~nm})$. Some of the new polymers with alternating donoracceptor architecture showed strong intramolecular charge transfer.
\end{abstract}

Keywords: $\mathrm{PQ}$

\section{Introduction}

Soluble polyquinolines can be used as the host in guest-host systems with either fluorescent or phosphorescent emissive dopants as has been done with other soluble polymers. 13 To achieve solubility in organic solvents, alkyl-substituted arylene groups 9,10 have been incorporated into the polymer backbone or the pendant phenyl group on the bis(4-phenylquinoline) has been alkylated.8 Alternatively,our group has synthesized a series of A-B monomers that self-polymerized into soluble regioregular poly(4-alkylquinoline)s.7 Although polyquinolines have been studied for over three decades, novel architectures such as diblock and triblock copolymers that facilitate self-assembly and side-chain polymers1 are still being explored. Similarly, the library of arylene groups being incorporated into quinoline copolymers is being expanded and becoming more exotic.8-10, This paper reports a new synthetic route to organic solvent-soluble conjugated polyquinolines in corporating bis(4-alkylquinoline) units through a new A-A monomer, 3,3'-dinonanoylbenzidine. A series of six new alternating conjugated copolymers, poly(2,2'-arylene4,4'-bis(4-alkylquinoline))s, exemplify the new synthetic methodology. Diverse n-type conjugated polymers that are soluble in organic solvents can thus be obtained by variation of the arylene linkage which facilitates the tuning of the electronic and optical properties. The arylene linkages shown in the polymers of include p-phenylene, 4,4'-biphenylene, stilbene, 5,5'-bithienylene, bis(thienyl) vinylene, and 3,7-phenothiazinylene, and they allowed the variation of the electron affinity in the $2.7-3.0 \mathrm{eV}$ range, the glass transition in the $110-254{ }^{\circ} \mathrm{C}$ range, and the electroluminescence color from blue-green, green, yellow, and orange to deep red.

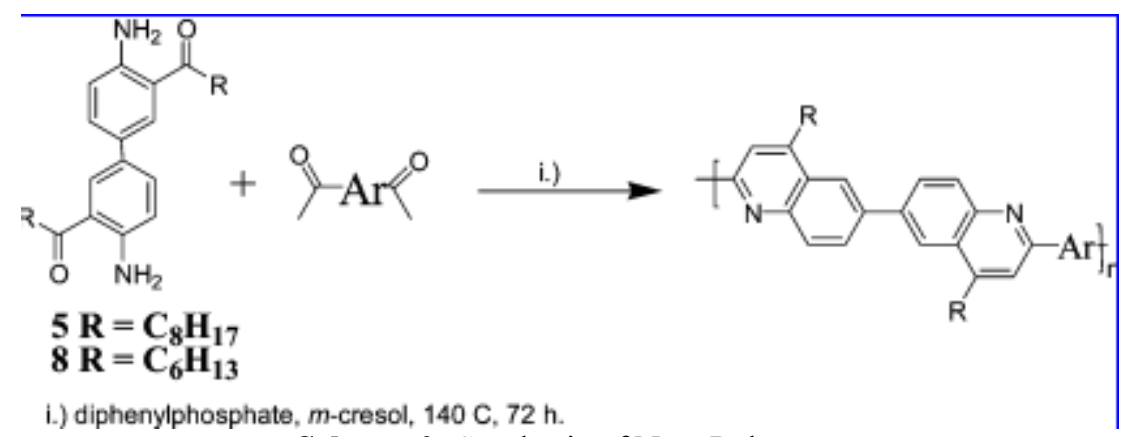

Scheme 2: Synthesis of New Polymers 
International Journal of Science and Research (IJSR)

ISSN (Online): 2319-7064

Index Copernicus Value (2013): 6.14 | Impact Factor (2014): 5.611

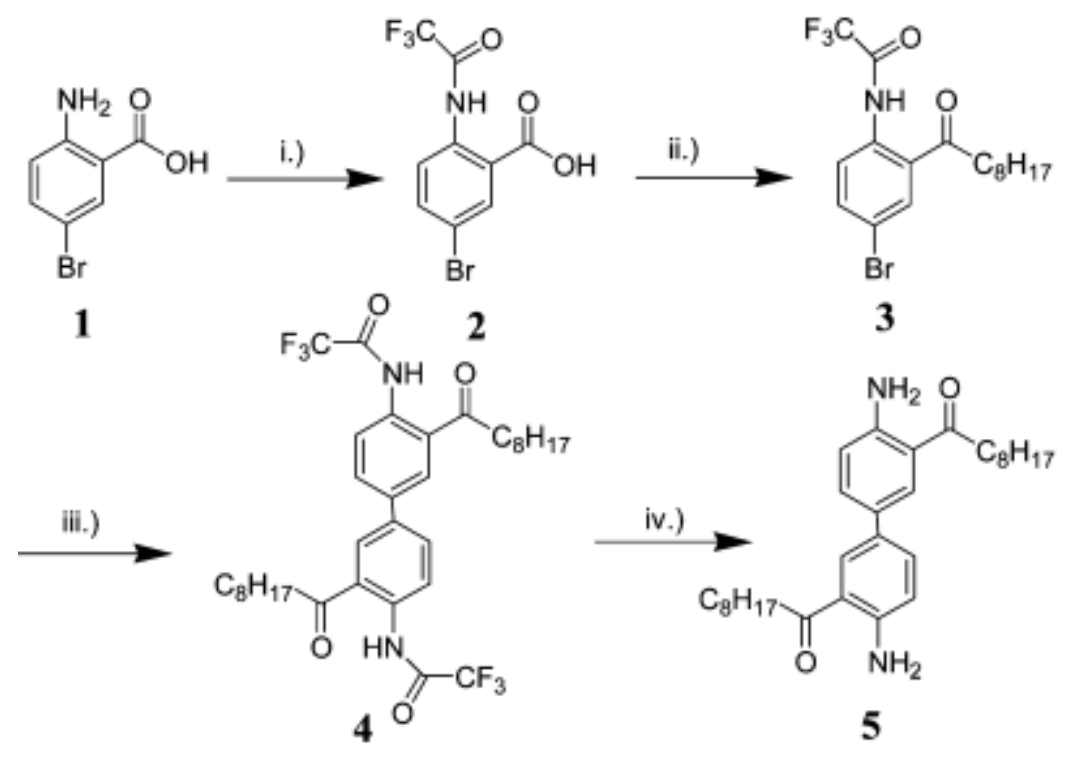

i.) TFAA, r.t. 1 h. ii.) $\mathrm{H}_{17} \mathrm{C}_{8} \mathrm{MgBr}$, THF, reflux 24 h. iii.) $\left[\mathrm{Me}_{3} \mathrm{Sn}\right]_{2}, \mathrm{Pd}\left[\mathrm{P}(\mathrm{Ph})_{3}\right]_{4}$, toluene reflux 24 h. iv.) $\mathrm{Na}_{2} \mathrm{CO}_{3}, \mathrm{H}_{2} \mathrm{O} / \mathrm{EtOH}$, relfux, 3d.

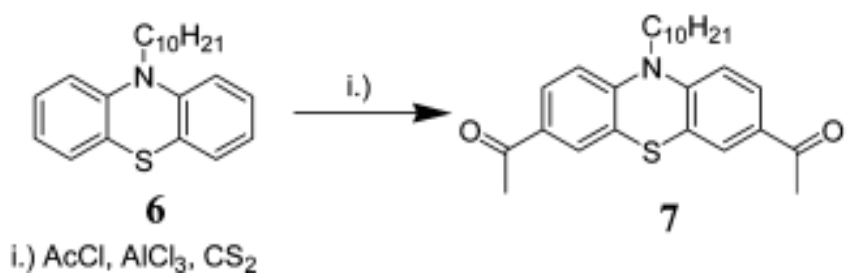

Scheme 1: Synthesis of New Monomers

\section{Results and Discussion}

\section{Synthesis and Characterization.}

The syntheses of the new monomers 5 and 7 are outlined in Scheme 1.The reaction of alkylmagnesium bromide withN-(trifluoroacetyl)-5-bromoanthranilic acid (2) is the crucial step in achievingo-(amino keto) functionality. Attempts to synthesize the monomer via Friedel-Crafts acylation of aniline, 4-bromoaniline, and benzidine were unsuccessful.N-Protected-5-bromo-2-nonanoylaniline was coupled under Stille conditions and then deprotected to achieve the 3,3'-dinonanoylbenzidine (5). The overall yield of the four-step synthesis was $24 \%$. Initial work targeted the 3,3'-diheptanoylbenzidine monomer (8), the synthesis of which is described elsewhere.10However, the poly(2,2'-(arylene)-6,6'-bis(4-hexylquinolines)) based on 8 had poor solubility, 10 leading us to increase the length of the alkyl chain from hexyl to octyl in the present study. Diacetyl monomers were copolymerized with the (o-amino keto)-functionalized 3,3'-dinonanoylbenzidine (5) to yield the new polyquinolines containing bis(4-octylquinoline) in the main chain (Scheme 2). 3,3'-Diheptanoylbenzidine (8) was initially used to synthesize several polymers containing bis(4-hexylquinoline); however, only PSHQ was sufficiently soluble in organic solvents and incorporated in the present study. The resulting products of polymerization were precipitated into $10 \%$ triethylamine/ethanol and extracted on a Soxhlet apparatus with $20 \%$ triethylamine/ethanol for 2 days to remove the diphenyl phosphate (DPP) acid catalyst.1H NMR and FT-IR spectra of the polymers confirmed the proposed structures. Thermogravimetric analysis (TGA) also indicated high purity with $<2 \%$ weight loss at the decomposition temperatures (TD). The weight average molecular weights (Mw), based on polystyrene standards and gel permeation chromatography (GPC), are shown in Table 1 . The $\mathrm{Mw}$ values range from 10000 for PPZOQ to 33900 for PBOQ, and the polydispersities were in the range of 1.26-4.90. These $\mathrm{Mw}$ values are generally lower than those previously reported for soluble poly(phenylquinoline)s $6 \mathrm{c}, \mathrm{d}$ but are similar to those of poly(4-alkylquinoline)s. 7 This indicates that replacing the phenyl group with an alkyl chain at the keto position of the A-A monomer may decrease the reactivity of the monomer. The much larger and broader molecular weight of PBOQ compared to the others reflects the geometry and reactivity of diacetylbiphenyl as also observed in prior phenylated polyquinolines. 11 The TGA thermogram of PBOQ is shown in Figure 1, indicating a decomposition temperature of 419 ${ }^{\circ} \mathrm{C}$.The decomposition temperature (TD) of the remaining polymers was in the range of $400-477{ }^{\circ} \mathrm{C}$ (Table 1).Typical second heating differential scanning calorimetry (DSC) scans for PPOQ and PBOQ are shown in Figure 2; these polymers show glass transitions ( $\mathrm{Tg}$ ) of 127 and $141{ }^{\circ} \mathrm{C}$, respectively. The Tg of the remaining polymers was between 110 and 254 ${ }^{\circ} \mathrm{C}$ (Table 1). Notably, the hexyl-substituted PSHQ had a significantly higherTg $\left(254{ }^{\circ} \mathrm{C}\right)$ than the octyl-substituted polyquinolines $\left(\mathrm{Tg}<170{ }^{\circ} \mathrm{C}\right)$, and PPZOQ (Tg)110 $\left.{ }^{\circ} \mathrm{C}\right)$, which contains both a decyl chain and two octyl chains per repeat unit, has the lowest $\mathrm{Tg}$. Poly(phenylquinoline)s typically have glass transitions between 200 and $400{ }^{\circ} \mathrm{C} .11$ The presence and length of alkyl chains has a significant 


\section{International Journal of Science and Research (IJSR) \\ ISSN (Online): 2319-7064 \\ Index Copernicus Value (2013): 6.14 | Impact Factor (2014): 5.611}

effect on the glass transition as evidenced in a series of poly-(phenylquinoline)s containing dialkylbithiophene moieties in the main chain; it was observed that the $\mathrm{Tg}$ decreased with increasing chain length. The high glass transitions of the new polyquinolines $\left(>110^{\circ} \mathrm{C}\right)$ suggest that they could withstand the joule heating associated with the operation of organic electronic devices.

Table 1. Physical Properties of New Polyquinolines

\begin{tabular}{|c|c|c|c|c|c|c|c|c|c|c|c|c|}
\hline polymer & $M_{W}\left(10^{4}\right)$ & PDI & $\begin{array}{l}T_{\mathrm{D}} \\
\left({ }^{\circ} \mathrm{C}\right)\end{array}$ & $\begin{array}{c}T_{\mathrm{g}} \\
\left({ }^{\circ} \mathrm{C}\right)\end{array}$ & $\begin{array}{c}\lambda_{\max }^{\mathrm{abs}} \\
(\mathrm{soln}) \\
(\mathrm{nm})\end{array}$ & $\begin{array}{c}\stackrel{\epsilon}{\epsilon} \\
\left(10^{4} \mathrm{M}^{-1} \mathrm{~cm}^{-1}\right)\end{array}$ & $\begin{array}{c}\lambda_{\max }^{\mathrm{abs}} \\
(\text { film) } \\
(\mathrm{nm})\end{array}$ & $\begin{array}{l}E_{\mathrm{g}}^{\mathrm{opt}} \\
(\mathrm{eV})\end{array}$ & $\begin{array}{c}\lambda_{\max }^{\mathrm{em}} \\
(\mathrm{soln}) \\
(\mathrm{nm})\end{array}$ & $\begin{array}{c}\lambda_{\max }^{\mathrm{em}} \\
(\mathrm{film}) \\
(\mathrm{nm})\end{array}$ & $\phi_{f}(\operatorname{soln})$ & $\phi_{f}($ film $)$ \\
\hline PPOQ & 1.5 & 1.82 & 421 & 127 & 375 & 2.3 & 386 & 2.85 & 417 & 493 & .18 & .05 \\
\hline PBOQ & 3.3 & 4.90 & 419 & 141 & 372 & 2.4 & 385 & 2.86 & 413 & 477 & .13 & .06 \\
\hline PSHQ & 1.9 & 2.74 & 477 & 254 & 398 & 1.4 & 409 & 2.67 & 431 & 524 & .11 & .04 \\
\hline PBTOQ & 1.5 & 1.45 & 400 & 128 & 436 & 2.3 & 443 & 2.35 & 483 & 615 & .16 & .01 \\
\hline PBTVOQ & 1.1 & 1.50 & 445 & 163 & 453 & 1.0 & 454 & 2.19 & 502 & 646 & .20 & .07 \\
\hline PPZOQ & 1.0 & 1.26 & 414 & 110 & 414 & 1.5 & 429 & 2.29 & 538 & 576 & .24 & .08 \\
\hline
\end{tabular}

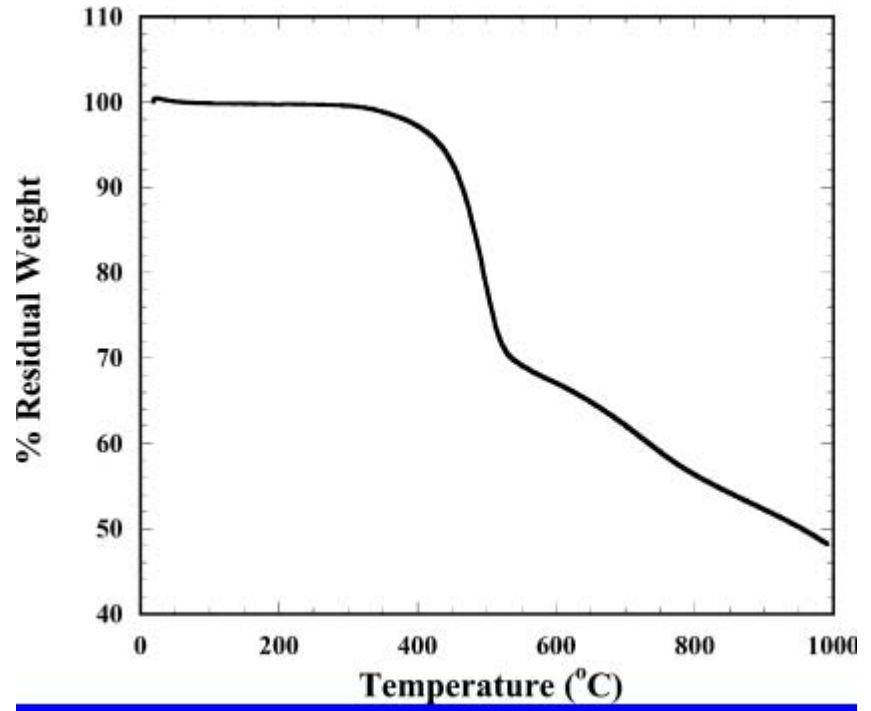

Figure 1: TGA curve of PBOQ at a scan rate of $10^{\circ} \mathrm{C} / \mathrm{min}$.

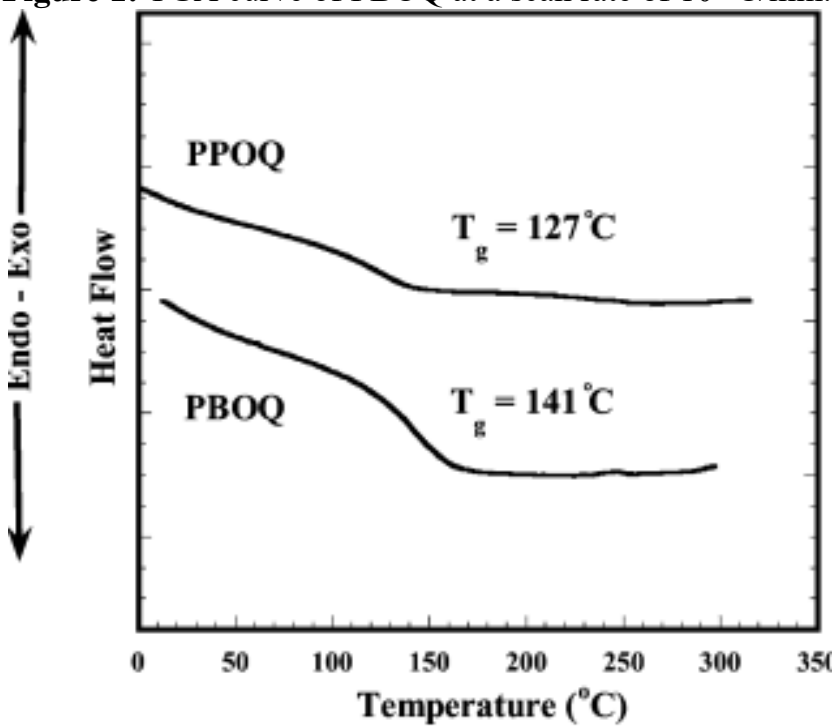

Figure 2: Second heating DSC curves of PPOQ and PBOQ (rate) $10^{\circ} \mathrm{C} / \mathrm{min}$ ).

The TGA thermogram of PBOQ is shown in Figure 1, indicating a decomposition temperature of $419{ }^{\circ} \mathrm{C}$.The decomposition temperature (TD) of the remaining polymers was in the range of $400-477{ }^{\circ} \mathrm{C}$ (Table 1).Typical second heating differential scanning calorimetry (DSC) scans for PPOQ and PBOQ are shown in Figure 2; these polymers show glass transitions ( $\mathrm{Tg}$ ) of 127 and $141{ }^{\circ} \mathrm{C}$, respectively.
The Tg of the remaining polymers was between 110 and 254 ${ }^{\circ} \mathrm{C}$ (Table 1). Notably, the hexyl-substituted PSHQ had a significantly higher $\mathrm{Tg}\left(254^{\circ} \mathrm{C}\right)$ than the octyl-substituted polyquinolines $\left(\mathrm{Tg}<170{ }^{\circ} \mathrm{C}\right)$, and PPZOQ (Tg)110 $\left.{ }^{\circ} \mathrm{C}\right)$, which contains both a decyl chain and two octyl chains per repeat unit, has the lowestTg. Poly(phenylquinoline)s typically have glass transitions between 200 and $400{ }^{\circ} \mathrm{C} .11$ The presence and length of alkyl chains has a significant effect on the glass transition as evidenced in a series of poly-(phenylquinoline)s containing dialkylbithiophene moieties in the main chain; $6 \mathrm{c}, \mathrm{d}$ it was observed that theTg decreased with increasing chain length. The high glass transitions of the new polyquinolines $\left(>110^{\circ} \mathrm{C}\right)$ suggest that they could withstand the joule heating associated with the operation of organic electronic devices.

\section{Electrochemical Properties}

Cyclic voltammetry was performed on thin films of the polymers coated onto $\mathrm{Pt}$ wire. Representative cyclic voltammograms (CVs) of four of the new polyquinolines are shown in Figure 3, and the corresponding electrochemical redox data are collected in Table 2 . CV scans on the polymers showed quasi-reversible reduction waves, similar to those of previously reported polyquinolines. 6 The formal reduction potential $\left(\right.$ Ered $\left.^{\circ \prime}\right)($ Epa+Epc)/2) varied from -2.0 V (vs SCE) for PPZOQ (Figure 3c) to-1.56 V for PBTVOQ. The onset reduction potential followed a trend similar to that of Ered ${ }^{\circ}$ in which PBTOQ and PBTVOQ have the most positive values. The solid-state electron affinity (EA) was estimated using the following relationship: EA )Ered onset +4.4 , where Ered onset is the onset reduction potential vs SCE.

The EA values range from $2.72 \mathrm{eV}$ for PPZOQ to $3.00 \mathrm{eV}$ for PBTVOQ, reflecting the modulation of the LUMO level by the arylene linkage. These values agree well with other polyquinolines which have been found to be useful n-type materials for OLEDs. 7,10 The electron-accepting bis(quinoline) moiety is present in all the polymers, which explains the little variation in electron affinity. However, variation of the arylene linkage provided a modulation of the oxidative properties of the polymers. PPOQ did not exhibit an oxidation wave in the potential range scanned in the CVs whereas PBOQ and PSHQ (Figure 3a,b) had irreversible oxidation peaks. PBTOQ (Figure 3d) and PBTVOQ, with thiophene linkages, showed a slight reversibility in their 


\section{International Journal of Science and Research (IJSR) \\ ISSN (Online): 2319-7064 \\ Index Copernicus Value (2013): 6.14 | Impact Factor (2014): 5.611}

oxidation waves, similar to that observed in analogous poly(phenylquinoline)s. PPZOQ, with the electron-rich phenothiazine group, showed a quasi-reversible oxidation peak (Figure 3c). The solidstate ionization potential (IP), estimated as IP)Eox onset +4.4 , whereEox onset is the onset oxidation potential vs SCE, varied from $5.17 \mathrm{eV}$ for PPZOQ to $5.96 \mathrm{eV}$ for PBOQ. The electrochemically derived band gap (Egel)of the new polyquinolines (Table 2) was 2.30-3.14 $\mathrm{eV}$. These values, as well as the estimated HOMO/LUMO levels, showed good agreement with previously reported, structurally similar poly(phenylquinoline)s. This indicates that the alkyl substitution at the 4-position had negligible effect on the electronic structure of the polymers.

Table 2. Electrochemical Properties of New Polyquinolines ${ }^{a, b}$

\begin{tabular}{|c|c|c|c|c|c|c|c|}
\hline polymer & $E_{\mathrm{red}} \mathrm{g}^{\prime}(\mathrm{V})$ & $E_{\mathrm{red}}^{\mathrm{esent}}(\mathrm{V})$ & $\mathrm{EA}(\mathrm{eV})$ & $E_{o x}^{\text {pank }}(\mathrm{V})$ & $E_{\text {ex }}^{\text {esert }}(\mathrm{V})$ & IP $(\mathrm{eV})$ & $E_{g}^{\mathrm{el}}(\mathrm{eV})$ \\
\hline PPOQ & -1.72 & -1.62 & 2.78 & n.o. & n.o. & n.o. & n.o. \\
\hline PBOQ & -1.78 & -1.58 & 2.82 & 1.92 & 1.56 & 5.96 & 3.14 \\
\hline PSHQ & -1.66 & -1.48 & 2.92 & 1.52 & 1.21 & 5.61 & 2.63 \\
\hline PBTOQ & -1.57 & -1.42 & 2.98 & 1.43 & 1.03 & 5.43 & 2.45 \\
\hline PBTVOQ & -1.56 & -1.40 & 3.00 & 1.31 & 0.90 & 5.30 & 2.30 \\
\hline PPZOQ & -2.00 & -1.68 & 2.72 & 0.99 & 0.77 & 5.17 & 2.53 \\
\hline
\end{tabular}

${ }^{a}$ All potentials vs SCE. ${ }^{b}$ Polvmers were coated onto Pt wire: $0.1 \mathrm{M}$ TBAPF $/ \mathrm{MeCN}$. Scan rate $=60 \mathrm{mV} / \mathrm{s}$.
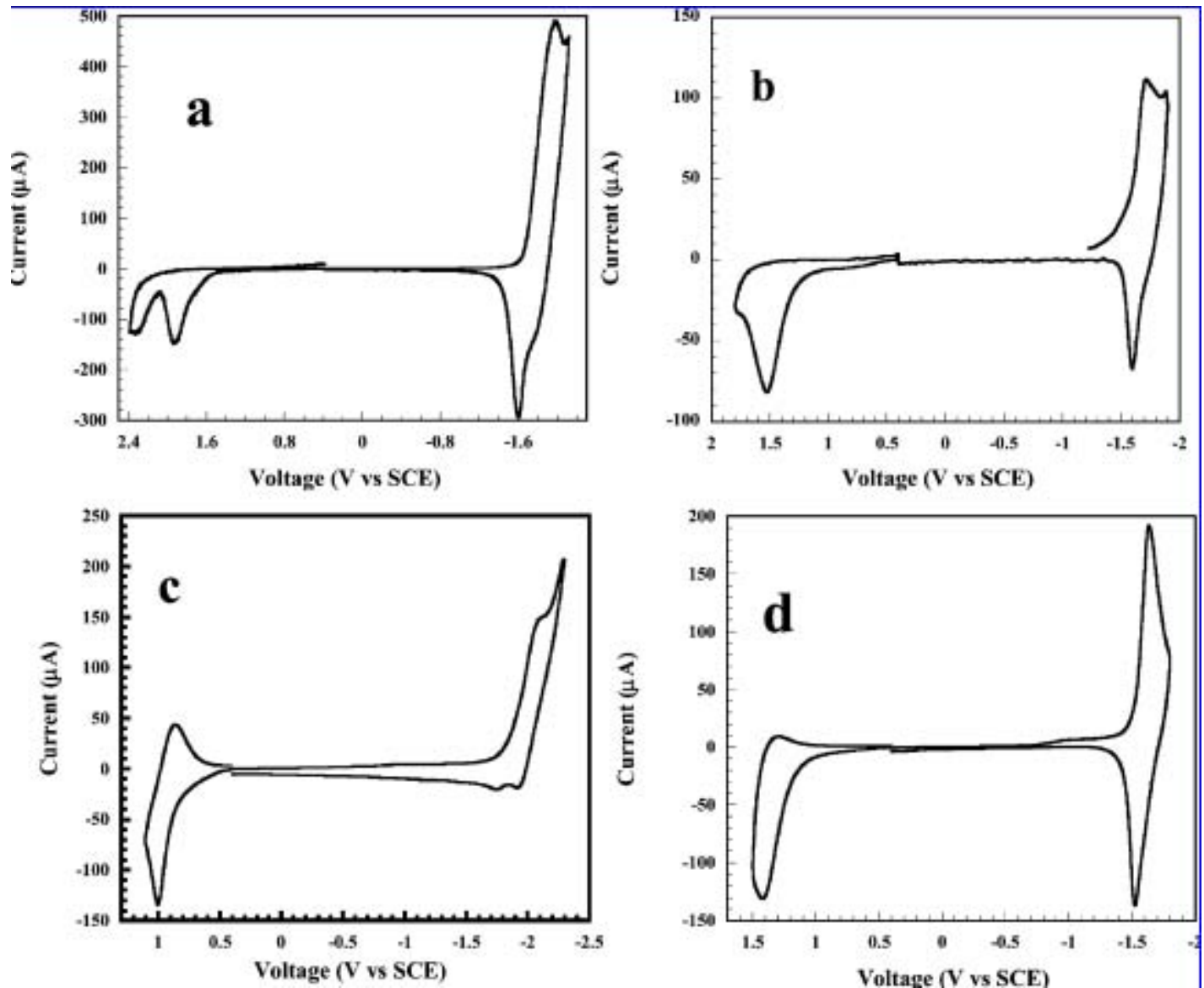

Figure 3: Cyclic voltammograms of thin films of PBOQ (a), PSHQ (b), PPZOQ (c), and PBTOQ (d) on Pt electrode. (0.1 M TBAF6 in MeCN; scan rate $) 60 \mathrm{mV} / \mathrm{s}$ ).

\section{Conclusion}

Synthesis of the key o-amino keto-functionalized monomer, 3,3'-dinonanoylbenzidine (5), was achieved by reacting alkylmagnesium bromide with the appropriate carboxylic acid. The new polymers derived from this monomer contained bis(4-alkylquinoline) in the main chain, facilitating solubility in organic solvents. The polymers had glass transitions of $110-254{ }^{\circ} \mathrm{C}$ and decomposed at above $400{ }^{\circ} \mathrm{C}$, proving them to be thermally robust materials suitable for application in organic electronic devices. By varying the arylene linkage in poly (2,2'-arylene-6,6'-bis(4-alkylquinoline))s from p-phenylene to bis (thienyl) vinylene, the optical band gap, redox properties, and electroluminescence color could be tuned over a wide range. The electron affinity or LUMO energy level of the polymers was in the range $2.72-3.00 \mathrm{eV}$, and blue-green, green,yellow, orange, and red electroluminescence colors were achieved with moderate brightness and efficiency. 


\section{Acknowledgement}

This research was supported by the Department of Chemistry, Government Vidarbh Institute of Science and Humanities, Amravati.

\section{References}

[1] [a] P.D. Sybert, W.H. Beever, J.K. Stille, Macromolecules 1981, 14, 493. [b] E.K. Zimmerman, J.K. Stille, Macromolecules 1985, 18, 321. [c] M.W. Pelter, J.K. Stille, Macromolecules 1990, 23, 2418.

[2] [a] A.K. Agrawal, S.A. Jenekhe, Chem. Mater. 1992, 4, 95. [b] A.K. Agrawal, S.A. Jenekhe, Macromolecules 1993, 26, 895.

[3] A.K. Agrawal, S.A. Jenekhe, Chem. Mater. 1996, 8, 579.

[4] M.A. Abkowitz, M. Stolka, H. Antoniadis, A.K. Agrawal, S.A. Jenekhe, Solid State Commun. 1992, 83, 937.

[5] A.K. Agrawal, S.A. Jenekhe, H. Vanherzeele, J.S. Meth, J. Phys. Chem. 1992, 96, 2837.

[6] S.A. Jenekhe, X. Zhang, X.L. Chen, V.-E. Choong, Y. Gao, B.R. Hsieh, Chem. Mater. 1997, 9, 409.

[7] D.M. Sutherlin, J.K. Stille, Macromolecules 1985, 18, 2669.

[8] G.S. Skinner, J.A. Gladner, R.F. Heitmiller, J. Am. Chem. Soc.1951, 73, 2230.

[9] R.B. Davis, L.C. Pizzini, J. Org. Chem. 1960, 25, 1884.

[10] S.A. Jenekhe, J.A. Osaheni, Science 1994, 265, 765.

[11] J.A. Osaheni, S.A. Jenekhe, J. Am. Chem. Soc. 1995, $117,7389$.

[12] J.H. Burroughes, D.D.C. Bradley, A.R. Brown, R.N. Marks, K. MacKay, R.H. Friend, P.L. Burn, A.B. Holmes, Nature 1990, 347, 539.

[13] N.C. Greenham, R.H. Friend, D.C.C. Bradley, $A d v$. Mater. 1994, 6, 491. 